\title{
Efficiency and safety of single dose Magnesium sulphate in eclamptic convulsion
}

\author{
Vinaya Goudar ${ }^{1 *}$, Rashmi Naganagoudaru ${ }^{2}$
}

\begin{abstract}
${ }^{1}$ Department of Obstetrics and Gynecology, Koppal Institute of Medical Sciences, Koppal, Karnataka, India
${ }^{2}$ Department of Obstetrics and Gynecology, Raichur Institute of Medical sciences, Raichur, Karnataka, India
\end{abstract}

Received: 05 May 2017

Accepted: 29 May 2017

\author{
*Correspondence: \\ Dr. Vinaya Goudar, \\ E-mail: vinigururajnayak@gmail.com
}

Copyright: () the author(s), publisher and licensee Medip Academy. This is an open-access article distributed under the terms of the Creative Commons Attribution Non-Commercial License, which permits unrestricted non-commercial use, distribution, and reproduction in any medium, provided the original work is properly cited.

\section{ABSTRACT}

Background: An acute and life-threatening complication of pregnancy is characterized by the appearance of tonic clonic seizures, in a patient with pre-eclampsia. Objective of the study was to study the efficacy and safety of a 'single dose' of magnesium sulphate in treatment of eclamptic convulsions.

Methods: The present prospective study was undertaken among women aged between 18-35 years outpatient's Department of gynecology in Karnataka Institute of Medical Sciences (KIMS) Hubli, Karnataka, India. The study was undertaken during December 2009 to November 2010.

Results: The incidence of eclampsia in our study was $2.12 \%$. Eclapmsia is more common in patients from rural $(89 \%)$ as compared to urban areas $(11 \%)$ in our study. In our study eclampsia is more common in unbooked cases $(80 \%)$. Majority of patients $(72 \%)$ in our study group were illiterates. $61 \%, 28 \%$ of patients had antepartum and intrapartum eclampsia respectively in our study. We had only 11 post-partum convulsions Table $2.80 \%$ of patients in our study were more than 28 weeks of gestations. $65 \%$ of the patients had $<5$ episodes of convulsions. The number of convulsions did not affect the recurrence, and $35 \%$ had $>5$ episodes. In present study 5 Patients had Systolic Blood Pressure less than $140 \mathrm{mmHg}$. Majority (52) had more than $160 \mathrm{mmHg} 42$ had in between 140 and $160 \mathrm{mmHg}$. Diastolic arterial pressure was $>110$ in $81 \%$ of cases. The convulsions were controlled in $75 \%$ of women. Recurrence of convulsions occurred in $25 \%$ of women after receiving the single dose magnesium sulphate regime. In our study $75 \%$ of cases, there was no recurrence of convulsions and in $25 \%$ of cases, there was recurrence of convulsions, out of which 20 cases received low dose magnesium sulphate regime and the other 5 cases received Phenytoin regime as $2^{\text {nd }}$ line of treatment.

Conclusions: Hence the single dose Magnesium sulphate is safe and effective in controlling convulsions.

Keywords: Convulsion, Eclapmsia, Magnesium sulphate regime

\section{INTRODUCTION}

An acute and life-threatening complication of pregnancy is characterized by the appearance of tonic clonic seizures, in a patient with pre-eclampsia. ${ }^{1}$ It is estimated to complicate 1 in 2000 deliveries in developed countries and from 1 in 100 to 1 in 1,700 deliveries in developing countries. $^{2}$ Eclampsia accounts for 50,000 maternal deaths a year worldwide. The maternal case fatality rate is $1.8 \%$ and $35 \%$ of eclamptics will have one major complication. ${ }^{3}$ The perinatal mortality rate in developing countries is as high as 80 (or) more per 1000 births. Magnesium sulphate was first used in the treatment of puerperal eclampsia in 1925. Pritchard (1955) published his initial experience with magnesium sulphate in the treatment of eclampsia. ${ }^{4}$ The first two randomized trials of anticonvulsant treatment in eclampsia were published in 1990. The Collaborative Eclampsia Trial (CET) 
involving 1687 women with eclampsia in the year 1995 provides compelling evidence that magnesium sulphate reduces the risk of recurrent seizures as compared with diazepam and phenytoin and also less maternal and neonatal morbidity than the other agents. ${ }^{5}$ Pritchard suggested that the dose of magnesium should be limited in women who are known to be or appear to be small. ${ }^{6}$ With this in mind the dose of regime of magnesium sulphate modified and a standardized protocol has been formulated to suit our Indian women who weight much less than counterpart in western world.

A Prospective study included 100 patients receiving single dose of magnesium sulphate therapy at Karnataka institute of medical sciences, Hubli from Dec 2009 to Nov 2010

The loading dose (4gm IV and 4 gm IM) of single dose regimen was significantly less than standard Pritchard regimen and other regimens, with this regimen the maternal mortality rate and perinatal mortality fallen dramatically. The objective of study was to study the efficacy and safety of a 'single dose' of magnesium sulphate in treatment of eclamptic convulsions.

\section{METHODS}

The present prospective study was undertaken among women aged between 18-35 years outpatient's Department of gynecology in Karnataka Institute of Medical Sciences (KIMS) Hubli, Karnataka, India. The study was undertaken during December 2009 to November 2010. Permission for the study was obtained from the College authorities prior to commencement.

Sample Size was 100 cases of Eclampsia between 20-42 weeks of pregnancy were taken in the study.

\section{Inclusion criteria}

All proved cases of eclampsia.

\section{Exclusion criteria}

Known epileptics, Patients who are put on other regimes and Eclamptic patients below 20 weeks and above 42 weeks.

\section{Data collection}

The objectives and methodology of the study were explained to those women who were included in the study. Apparently 100 women of those aged between 1835 years who voluntarily willing for the examination were taken in this study. Willing patients were enrolled into the study information has obtained us for the proforma.

A detailed history regarding age, parity, gestational age, number of convulsions, duration of symptoms of pregnancy induced Hypertension, H/0 imminent symptoms were taken from close relatives and also from the patient if she is conscious (or) taken retrospectively from her. Any past history of hypertension (or) renal disease (or) eclampsia in previous pregnancy was elicited.

A thorough general examination and obstetric examination were made. On general examination, conscious level, degree of edema, anaemia, pulse rate, temperature, respiratory rate, blood pressure, cardiovascular system, respiratory system, fundus examination was done. Blood and urine were sent for all investigations related to eclampsia like renal function tests, liver function tests, haematological tests and coagulation screening tests were carried out in all patients. A life line was established and the Regimen was started. Pulse, Blood pressure, Respiratory rate, Oxygen saturation monitored for every 30 minutes, Knee jerk and urine output every half hourly.

\section{Anti-convulsant line of management}

Women admitted to eclampsia labour room is given loading dose of $4 \mathrm{gm}$ of $50 \%$ IV magnesium sulphate diluted in $20 \mathrm{cc}$ of $5 \%$ of dextrose over 10-15 minutes, simultaneously $4 \mathrm{gm}$ of magnesium sulphate. Intramuscularly, $2 \mathrm{gm}$ on each buttock was administered.

The patient is monitored with Adequate anti hypertensives, hydration and immediate termination of Pregnancy. If the convulsions are not controlled even after 30 minutes of giving single dose magnesium sulphate, then it is switched over to other regimes like low dose magnesium sulphate and Phenytoin regime. Control of hypertension is achieved by Tab. Nifibipine $10 \mathrm{mg}$ Thrice day maximum of $120 \mathrm{mg}$ in conscious patients and injection lebetalol $20 \mathrm{mg}$ IV maximum of $300 \mathrm{mg}$ in unconscious patients.

\section{Obstetric management}

After stabilizing the patient, a detailed obstetric examination was done. Mode of termination was planned according to the gestational age, viability of the fetus, and the cervical scoring.

Patients were induced with prostaglandin E1 and accelerated with Oxytocin infusion. Cesarean section was done for obstetric indications (or) for failed induction. After delivery, the patient was observed carefully for 4872 hours in the labour ward and post-operative ward and followed up until the discharge of the patient.

\section{Outcome measures}

Primary outcome measures were recurrence of fits, safety and efficacy after starting the treatment in single dose regime. 


\section{Stastical analysis}

Data collected was entered in Microsoft Office Excel and analyzed by using SPSS version 13.0. Dependent variable frequencies, percentage, were calculated.

\section{RESULTS}

The present study about the efficacy and safety of Single dose magnesium sulphate in eclampsia patients. This study consists of 100 cases of eclampsia admitted to Karnataka Institute of Health Sciences, Hubli, Karnataka, India from December 2009 to November 2010. Majority of patients belong to lower socio-economic status, majority of them were Hindus. Total no of deliveries during December 2009 to November 2010 were conducted 8100 . Among total deliveries there were 172 eclampsia cases. The incidence of eclampsia in our study was $2.12 \%$ (Table 1 ).

Table 1: Incidence of eclampsia.

\begin{tabular}{|ll|}
\hline Total no of deliveries & $\mathbf{8 1 0 0}$ \\
\hline Total no of eclampsia cases & 172 \\
\hline Incidence of eclampsia & 2.12 \\
\hline
\end{tabular}

Eclapmsia is more common in patients from rural (89\%) as compared to urban areas (11\%) in our study. In our study eclampsia is more common in unbooked cases (80\%). Out of 20 booked cases 16 cases were booked outside KIMS and 4 patients were booked at KIMS. Majority of patients $(72 \%)$ in our study group were illiterates. In our study eclampsia is more common in women aged 25 years or below (80\%) and there is decrease in incidence in women aged $26 \mathrm{yrs}$ or more. $75 \%$ of patients encountered in this study were primigravidas (Table 2).

Table 2: Relation with parity.

\begin{tabular}{|lll|}
\hline Parity & No. of cases & $\%$ \\
\hline P0 & 75 & 75 \\
\hline P1 & 16 & 16 \\
\hline P2 & 8 & 8 \\
\hline P3 & 1 & 1 \\
\hline
\end{tabular}

$61 \%, 28 \%$ of patients had antepartum and intrapartum eclampsia respectively in our study. We had only 11 postpartum convulsions (Table 3 ).

Table 3: Type of eclampsia.

\begin{tabular}{|lll|}
\hline Type of eclampsia & No. of cases & $\%$ \\
\hline Antepartum & 61 & 61 \\
\hline Intrapartum & 28 & 28 \\
\hline Postpartum & 11 & 11 \\
\hline
\end{tabular}

$80 \%$ of patients in our study were more than 28 weeks of gestations. 45 cases were conscious at the time of admission. 6 patients were unconscious at the time of admission. $65 \%$ of the patients had $<5$ episodes of convulsions. The number of convulsions did not affect the recurrence, and $35 \%$ had $>5$ episodes

Convulsions to treatment interval was $6 \mathrm{hrs}$ in $74 \%$ of cases and more than 6 hours in 26\% cases. Which shows the precious time was wasted instead they could have received treatment at peripheral centre only. In present study 5 Patients had Systolic Blood Pressure less than $140 \mathrm{mmHg}$. Majority (52) had more than $160 \mathrm{mmHg} 42$ had in between 140 and $160 \mathrm{mmHg}$. Diastolic arterial pressure was $>110$ in $81 \%$ of cases. This showed that control of blood pressure is an important step in management of eclampsia. The convulsions were controlled in $75 \%$ of women.

Recurrence of convulsions occurred in $25 \%$ of women after receiving the single dose magnesium sulphate regime. In our study $75 \%$ of cases, there was no recurrence of convulsions and in $25 \%$ of cases, there was recurrence of convulsions, out of which 20 cases received low dose $\mathrm{MgSO} 4$ regime and the other 5 cases received Phenytoin regime as $2^{\text {nd }}$ line of treatment (Table 4).

Table 4: Recurrence of convulsions $\left(2^{\text {nd }}\right.$ line of treatment).

\begin{tabular}{|lll|}
\hline $2^{\text {nd }}$ line treatment & No of cases & $\%$ \\
\hline Low dose magnesium sulphate & 20 & 20 \\
\hline Phenytoin & 5 & 5 \\
\hline
\end{tabular}

\section{DISCUSSION}

Incidence of eclampsia in our study was $2.12 \%$ (Table 1 ). The incidence of eclampsia varies from country to country and from zone to zone in the same country, poor antenatal care, low socio-economic status and illiteracy are responsible for higher incidence of eclampsia. ${ }^{8-9}$

Table 5: Comparative incidence of eclampsia reported by different authors in India.

\begin{tabular}{|ll|l|}
\hline Authors & Year & Incidence in \% \\
\hline Goswami et al & 1983 & 4.62 \\
\hline Sonyal MK et al & 1987 & 2.69 \\
\hline Bhattacharya PK & 1992 & 0.7 \\
\hline Swain & 1992 & 2.2 \\
\hline Present study & $2009-10$ & 2.12 \\
\hline
\end{tabular}

In present study, the incidence of eclampsia is highest in the younger age group. The incidence of eclampsia in the age group less than 25 yrs was $80 \%$. This is comparable to study by Nobis PN (1988) women aged <25 yrs was $84.16 .{ }^{10}$ Incidence of eclampsia in un registered cases was $80 \%$ and in registered cases it was $20 \%$. Cause of difference in incidence of eclampsia between the two groups may be due to early diagnosis and prompt treatment in registered cases, timely admission and early intervention. Majority of patients in our study were primigravidas. They constituted $75 \%$ of patients. In study 
of Gun et al 1980, incidence of eclampsia in primigravida was $67.57 \%$. In study by Dutta incidence of eclampsia in primigravida was $88.2 \% .^{11}$

$61 \%$ of patients had antepartum eclampsia. $28 \%$ of patients had intrapartum eclampsia. He reported that $44 \%$ had AP eclampsia, 33\% had IP and $23 \%$ had PP eclampsia. According to Arias $\mathrm{F}$ the incidence of AP eclampsia is $46.3 \%$, IP16.4\% and IP-37.3\%. ${ }^{12}$ Katz et al reported $53 \%$ AP, $36 \%$, IP and $11 \%$ PP cases. $65 \%$ of the patients had $<5$ episodes of convulsions. The number of convulsions did not affect the recurrence, and $35 \%$ had $>5$ episodes. In study by Dutta GP and Swain et al as the number of convulsions increases maternal mortality and perinatal mortality increases. ${ }^{9}$ In the present study, majority of patients had diastolic blood pressure more than 110. In Collaborative Eclampsia Trial Group study (1995) 53\% had a diastolic blood pressure above or equal to $110 \mathrm{~mm} \mathrm{Hg}{ }^{13}$

In $75 \%$ of cases, there was no recurrence of convulsions and in $25 \%$ of cases; there was recurrence of convulsions after receiving the single dose regime. The serum $\mathrm{MgSO}_{4}$ could not be estimated in these cases as we had no laboratory facility to estimate in our set up so we could not estimate whether the $\mathrm{MgSO}_{4}$ levels were in therapeutic range or not. Safe monitoring was achieved without serum magnesium measurement using simple clinical assessment of tendon reflexes, respiratory rate and urine output. None of the patients had adverse effect of magnesium sulphate toxicity.

\section{CONCLUSION}

This study reveals that Magnesium Sulphate is the anticonvulsant drug of choice in women with eclampsia. This regime promises efficacy, reliability, ease of administration (phenytoin needs cardiac monitoring), easy nursing, predictable duration of action, wide safety margin, early availability, cheaper relatively less toxic and needs no serum monitoring. Hence the single dose Magnesium sulphate is safe and effective in controlling convulsions. Hence this study encourages to undertake large trials to prove its efficacy and safety.

\section{ACKNOWLEDGMENTS}

Authors would like to thank the participants for their cooperation and for their immense faith they reposed.
Funding: No funding sources

Conflict of interest: None declared

Ethical approval: The study was approved by the Institutional Ethics Committee

\section{REFERENCES}

1. Sibai BM. Diagnosis, prevention, and management of eclampsia. Obstet Gynecol. 2005;105(2):402-10.

2. Duley L. Pre-eclampsia and the hypertensive disorders of pregnancy. Br Med J. 2003;67:161.

3. Sibai BM, Taslimi M, Abdella TN. Maternal and perinatal out-come of severe pre-eclampsia in midtrimester. Am J Obstet Gynecol. 1985;152:32.

4. Pritchard JA, Cunningham FG, Pritchard SA. The Parkland Memorial Hospital protocol for treatment of eclampsia: Evaluation of 245 cases. Am J Obstet Gynecol. 1984;148:951.

5. Group TE. Which anticonvulsant for women with eclampsia? Evidence from the Collaborative Eclampsia Trial. Lancet. 1995;345(8963):1455-63.

6. Pritchard JA. The Park land memorial hospital, protocol for treatment for eclampsia: Evaluation of 245 cases. Am J Obstet Gynecol. 1984:148:951-63.

7. Sanyal MK, Bhattacharya A, Pattanayak K. A clinical review of eclampsia in rural medical college of West Bengal. J Obstet Gynaecol India. 1987;37:797.

8. Bhattacharya PK, Purkayastha S, Basu M, Mandal R. Caesarean Section in Eclampsia: Still a dilemma analysis of 314 cases. J Obstet Gynecol. 1992;42(1):51.

9. Swain S. Maternal and perinatal mortality due to Eclampsia. J Indian Paediatr. 1993;30(6);771-3.

10. Nobis PN. Perinatal Mortality in eclampsia. J Obstet Gynecol India. 1998;38:38-42.

11. Dutta DC. Text book of Obstetrics. $3^{\text {rd }}$ Edition; 1992.

12. Fernando A. High risk pregnancy and delivery. $2^{\text {nd }} E d ; 1993$.

Cite this article as: Goudar V, Naganagoudaru R. Efficiency and safety of single dose Magnesium sulphate in eclamptic convulsion. Int J Reprod Contracept Obstet Gynecol 2017;6:3058-61. 